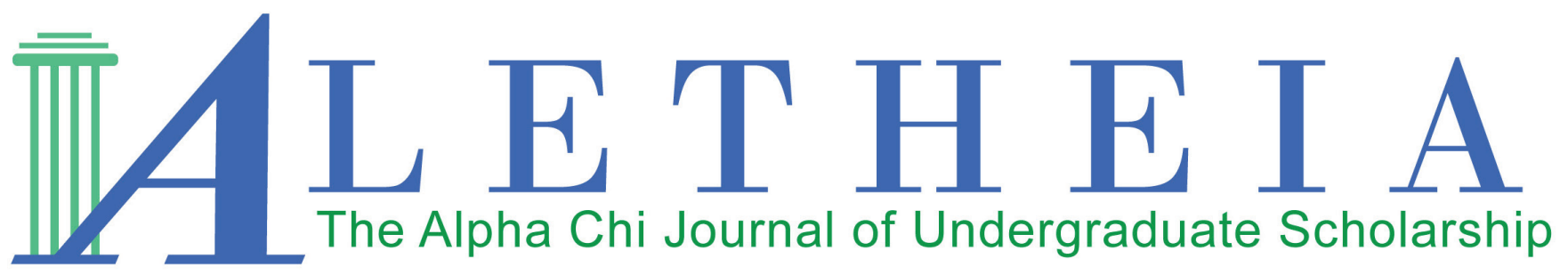

Volume 2 | Issue 1 | 2017

\title{
American Eugenics and Involuntary Sterilization
}

\author{
Bryen Farrell Pittner \\ Marymount Manhattan College \\ New York Iota Chapter
}

Vol. 2(1), 2017

Article Title: American Eugenics and Involuntary Sterilization

DOI: $10.21081 / \mathrm{AX} 0093$

ISSN: 2381-800X

Key Words: eugenics, involuntary sterilization, population control, America, reproductive rights This work is licensed under a Creative Commons Attribution 4.0 International License.

Author contact information is available from the Editor at editor@alphachihonor.org.

\section{Aletheia-The Alpha Chi Journal of Undergraduate Scholarship}

- This publication is an online, peer-reviewed, interdisciplinary undergraduate journal, whose mission is to promote high quality research and scholarship among undergraduates by showcasing exemplary work.

- Submissions can be in any basic or applied field of study, including the physical and life sciences, the social sciences, the humanities, education, engineering, and the arts.

- Publication in Aletheia will recognize students who excel academically and foster mentor/mentee relationships between faculty and students.

- In keeping with the strong tradition of student involvement in all levels of Alpha Chi, the journal will also provide a forum for students to become actively involved in the writing, peer review, and publication process.

- More information and instructions for authors is available under the publications tab at www.AlphaChiHonor.org. Questions to the editor may be directed to editor@alphachihonor.org.

\footnotetext{
Alpha Chi is a national college honor society that admits students from all academic disciplines, with membership limited to the top 10 percent of an institution's juniors, seniors, and graduate students. Invitation to membership comes only through an institutional chapter. A college seeking a chapter must grant baccalaureate degrees and be regionally accredited. Some 300 chapters, located in almost every state, induct approximately 12,000 members annually. Alpha Chi members have been "making scholarship effective for good" since 1922.
} 


\title{
American Eugenics and Involuntary Sterilization
}

\author{
Bryen Farrell Pittner
}

\author{
Marymount Manhattan College \\ New York Iota Chapter
}

\begin{abstract}
Due to eugenics, 65,000 Americans were sterilized without informed consent between 1907 and 1963, over half of whom were women (Reilly 161). This paper investigates the ideology, laws, and health practices and programs that allowed so many marginalized populations to be disproportionately affected by the population control movement. An analysis of pro-eugenics actions and their effects provides a clear framework by which to understand the choice or lack thereof concerning motherhood in 20th century America.
\end{abstract}

Keywords: eugenics, involuntary sterilization, population control, America, reproductive rights

\section{Introduction}

As a result of the American Eugenics Movement, between 1907 and 1963, at least 65,000 Americans were sterilized without consent, over half of whom were women (Reilly 161). Eugenics is the belief that "better" genetic quality improves public health. Employing eugenics, a population control movement swept the United States from the beginning of the 20th century. Offering family planning programs and contraceptives to women, different foundations such as the American Eugenics Society, Population Council, Population Reference Bureau, and Planned Parenthood promoted not only the social implications of population growth, but the choice of motherhood. What follows will investigate the pro-eugenics logic used to justify the controversial population control politics in 20th century America.

With the influx of immigrants, urban sprawl, and industrialization, eugenicists led by Malthusianism ideology incited social constructions and legislation, coercing many marginalized populations including racial and ethnic minorities, poor, socially stigmatized, diseased, and handicapped people into involuntary sterilization. "Malthusianism" refers to Thomas Malthus' study of constrained resources not sustaining unchecked population growth, thus much of eugenic actions were in an effort to better society, although resulted in many minority women losing the right to control their fertility. Pro-eugenicists moved to aggressively increase reproductive control over marginalized populations for fear of a shrinking Anglo-Saxon middle class, creating a divide of pro- and anti-eugenics groups. By looking at the application of Malthusianism, fertility-control methods, federal spending on welfare, public opinion toward the "unfit," and the feelings of the "unfit," this paper will examine the heated discussion on American eugenics spanning the 20th century. 


\section{Definitions and Organization}

An individual or group in favor of eugenics and population control will be referred to as "pro-eugenic," "pro-sterilization," or "eugenicists."

"Reproductive control" will refer to sterilizations, intrauterine devices (IUDs), and other fertility/birth control methods because they all inhibit pregnancies. Medical and illegal abortions were common practice in this time period as well, but this research involves preventive birth control methods. Involuntary female sterilizations will be primarily examined because sterilizations were the most common and extreme action behind the pro-eugenics movement in America.

This paper investigates the related ideology which led to the international popularity of population control followed by increased pressure on the welfare system, ultimately leading to the legislation and sociology behind the eugenics movement. The consequences of involuntary sterilization are studied through various court cases, statistics, and historical accounts.

\section{Ideological Roots}

Justification for population control stems from Malthusianism, named for the population control movement's earliest modern advocate, Thomas Robert Malthus (1766-1834) (Farmer 1). His ideology grounded the eugenics argument in social, economic, and moral spheres, making it possible for the eugenics movement to be legitimized and thrive in America. His ideology can be summed up in three key ideals. First, Malthus provided a functional analysis of poverty, welfare, and population growth. Will there be enough? Will future technologies take care of shortages? Second, Malthus valued achieving the greatest good for the greatest number of people. Third, he prioritized human liberty.

Malthus reminds us that reproduction should not increase without certain production quotas, yet the Industrial Age introduced an urban swell that could not sustain itself. While Industrialism gleaned huge profits, poor people's wages were inequitably depressed. The one commodity that poor people could provide, labor, became incredibly inexpensive in this era, meaning that laborers could barely cover expenses, let alone those of dependents (Elwell 23). With a greater number of people requiring more goods such as food, prices increased and fewer people had access to essentials (Elwell 23, 26).

Not able to thrive in the free market, many people were forced to turn to welfare. However, Malthus was against welfare because he argued it enabled dependence and destroyed human liberty. According to Malthus, if you implement aid, you are "exercising power over the life affairs of all who are forced to ask for support" (Elwell 24). He viewed welfare as innately tyrannical in that it imposes without encouraging or even providing individual choice. By extension, with the capacity to be an asset and sustain one's own family comes the ability to attain autonomy, dignity, and freedom.

Malthus proposed that people are more likely to make independent decisions if given the responsibility and resources to do so. Given liberty, he argued, people would be able to exercise rationality to make educated choices about family size based on a cost-benefit analysis (Elwell 17). Potential parents might ask themselves questions such as, "Will having children decrease my life quality or that of other dependents?" or "Will I need to rely on charity to provide for my children?" (Elwell 17). These questions bring up notions of utilitarianism, another principle in tandem with Malthus' conception of liberty.

Utilitarianism dictates that something is right so long as it promotes the greatest good for the greatest amount of people. In application to population control, Malthus believed that people should exercise moral restraint in reproducing so that quality of life will be greater: "the numbers of the poor would increase, production (particularly food) would not, everybody's share in a stable output would therefore decrease" (Elwell 28). Pursuing this preventive check on population, he argued, the poor would be able to provide themselves with a more pleasurable life, struggling less to acquire food and other resources. Resources such as products or programs are necessary for making family planning decisions, as is personal liberty; the eugenics movement provided the former and exploited the latter.

Rooted in Malthus' theory, but obscured by modern society, population control turned into an aggressive eugenics movement resounding throughout America. An international stakeholder consensus followed by racial tension and an increase in welfare dependents allowed eugenicists to point a finger at society's most vulnerable.

\section{International Stakeholders}

Nearly a hundred years after Malthus' work, fears of over-population of the "wrong sort" of people prompted such meetings as the International Congress of 1912. Topics like "racial decay" and miscegenation brought population control politics to the forefront of European 
and American change-makers such as Winston Churchill, Leonard Darwin, and Charles B. Davenport, director of the Eugenics Record Office in New York (Kuhl 14). Congress discussed how best to implement legislation and action for racial pure-breeding (Kuhl 14). This topdown approach put white men in control of women's bodies and bodies of color. Soon after these international meetings, America received praise from German eugenicists for enacting strict legislative action to reduce the number of "inferior births" (Kuhl 16). A World War I era flyer from the Society for Racial Hygiene in Berlin reads, "Can we have any doubts that the Americans will reach their aim - the stabilization and improvement of the strength of the people?" (Kuhl 16) "Improvement" referred to the increase in white, healthy, middle-class citizens. Once early American eugenicists began setting up commissions, writing books, and gaining legislative traction, there was further investigation into what burdens the "less desirable" people inflicted on the American government, prompting a surge of reproductive control legislation and funding. America was most prominent in the international eugenics debate in the earliest part of the century, although the number of people sterilized did not peak until the 1930s-40s (Reilly 162). Other factors gained momentum which will be examined before covering federal and legislative actions.

\section{Federal Spending}

In Christopher Chantrill's graphs, "Welfare Spending: Charts for US Governments," there is progressive spending in Medicaid and government health care, especially from 1920 to 1940 , showing the government's investment in those on welfare. Welfare spending on programs for relief, unemployment compensation, and income support led to an all-time high in welfare spending in 1940, in the midst of the Great Depression. There was also a call for a reformation of how taxpayer money was spent on social security and other public health efforts: "If the government did not intervene, eighteen million people burdened by disease or mental defect would become the charge and burden on the rest of the population, the [Human Betterment] Foundation declared" (Kline 107). The funding gaps and increased need for government support made reproductive control more fiscally attractive. Funding monthly birth control pills or a single sterilization was much less expensive than supporting another person on welfare.

\section{Social Divide and Blame}

Questions of an individual's value and right to reproduce arose with the social tension post-Depression and pre-Civil Rights Movement. According to Natalia Molina, "The interdependent theories of race suicide and race betterment posited that as white women's birth rates dropped, those of immigrant women rose" (110). Racial division and whites' fear of losing a white majority led to a desire to have power over minorities. Other factors by which to sort one's "fitness" to reproduce arose from the masses too: Mid-century journalist Fred Hogue claimed, "In this country we have wiped out the mosquito carriers of yellow fever and are in a fair way to extinguish the malaria carriers: but the human breeders of the hereditary physical and mental unfit are only in exceptional cases placed under restraint" (“STERILIZED” 1130). Hogue wondered why the United States would not extract disability from the population, placing what he believed to be overall public health over individual rights (Kline $98,107)$. He was not alone: "Thousands of letters from students, professors, ministers, rabbis, social workers, public health and welfare workers, Rotary Club members, physicians, librarians, birth-control advocates, and Parent Teacher Assoc. members expressed personal support and interest in eugenic sterilization as the 'only logical and human method of protecting ourselves' from the rising tide of degeneracy" (Kline 80).

\section{Target Populations}

International stakeholders, as well as the American government and society, identified key groups unworthy of reproducing. Most broadly, marginalized women were most commonly targeted. According to Stefan Kuhl, "One prominent German sterilization expert, Otto Kankeleit shared the notion with his pro-eugenics colleagues that "the number of 'degenerate' individuals depended mainly on the number of 'degenerate' women." In Kankeleit's words, "The sterilization of the degenerate woman is more important than that of the man" (25).

Eugenics, or the cleansing of certain biological factors to rear the ideal population, was racially motivated. According to Molina, "Women of color often are cast as sexually and intellectually aberrant and therefore in need of being taught normative behavior or controlled" (Molina 185). Xenophobia against Mexican and Japanese immigrants and Native Americans also instigated eugenic offenses. 
In addition to white-supremacist values, the eugenics movement often targeted poor white women. Rickie Solinger demonstrates that "Like Black women, these [poor white] women were excluded from the category of white nation-building mother, despite racial identity" (49). Simply because of class status, white women were not treated with the white privilege that their elite counterparts were, although they were not nearly as disadvantaged as poor women of color. There was also the fear that "mentally defective, sexually immoral" white women would "pose a major threat to the evolutionary supremacy of the white race" (McWhorter 167). Furthermore, Solinger points out that "in professional journals, at charity agencies, in the courts, and elsewhere, experts described the sexuality of poor women and women of color as hot, rapacious, and dangerous, a public menace, and an appropriate target of restraints" (80). Anyone who is mentally disabled or socially stigmatized for sexual behavior was believed not to be fit for reproducing, especially if that person were white and more likely to "poison" the race. However, socio-economic vulnerability compounded with racism put the black and brown bodies of poor immigrant women most at risk.

Additional circumstances such as chronic disease or physical disability, e.g. blindness, amplified discrimination: Members of The Committee on Race Psychiatry "suspected that 'inferior' races were more likely to show a higher rate of mental retardation, schizophrenia, and manic depression' than the white race" (Kuhl 22). These at-risk populations were in need of reproductive control methods, but at the mercy of federal welfare programs designed to promote white, able-bodied breeding for a "purer" American population.

\section{Reproductive Control Methods}

In the guise of supplying family planning products and increased reproductive control rights, eugenicists incited control over who reproduces. The majority of coercive fertility control victims were women because their bodies were and continue to be less socially respected and most often in vulnerable medical settings, such as giving birth.

Although a myriad of products and procedures existed in the 20th century, the varying forms of birth control made available to women across races and classes were indicative of what kind of reproductive future lay ahead. Other than barrier birth control methods such as condoms and diaphragms, there are three categories in which we can place fertility control methods: short-term, including hormonal pill contraceptives; long-term, such as IUDs; and permanent, i.e. sterilization. In this study, tubal ligation procedures were the most common of all sterilization procedures.

Middle-class white women could afford to control their fertility through non-permanent methods like oral contraceptives or IUDs. These women generally planned on having children, but only when their solid economic and marital statuses and economic comfort made the choice to have children appropriate.

Disfranchised women hoping to control their fertility were at the mercy of public policy initiatives (Solinger 219). It was not long before the government and physicians calculated a single sterilization to be much less expensive than multiple abortions, IUD insertions, or monthly birth control prescriptions. In the 1960's, at the rise of the "pill's" popularity, pharmacists would only sell one month's worth at a time to women on Medicaid, realizing that government reimbursements were slow and not wanting to risk monetary losses (Solinger 172). With only one month of pills at a time, poor women could not sustain consistent daily dosage, deeming this method impractical.

In desperation to control their bodies, some women soon turned to sterilization, for which Medicaid paid 90\% in 1971 (Solinger 194). However, medical professionals often gave misinformation, and the sterilizations were often given without proper consent. The Hyde Amendment was enacted three years after Roe v. Wade in 1976, as the first attempt at denying poor women access to government-funded abortions (Solinger 200). As a result, many women found sterilization to be the only viable option because it was the only one they could afford (Solinger 219). Further, it seemed to be the only option that the United States could spare in an effort to be "pure" (McWhorter 230-31). Again, the notion of white supremacy weaves itself into pro-eugenics actions.

Additionally, many fertility control advocates, such as the president of Planned Parenthood in the 1960's, Alan Guttmacher, did not trust women to fully understand nor use the pill properly. Poor women lacking affordable coverage or the "capacity" to handle oral contraceptives were sterilized or fitted with IUDs (Solinger 170). According to Solinger, "Guttmacher particularly liked the fact that 'once the damn thing 
[IUD] is in, the patient cannot change her mind" (171). The lack of trust in women only escalated when race or socio-economic class factors came into play. In reference to IUD insertions, "A North Carolina official explained, 'Some of these people, particularly the colored people, are apt to misinterpret the procedure and conclude that the method used once becomes effective for all time" (Solinger 116). Sexist and racist statements such as these completely undermined any progress for women in need of control over their fertility. No doubt women wanted to control their own childbearing, as it was in their best interest, but the eugenics movement controlled it for them. Women were left with no choice as to how and sometimes when fertility might be curbed or allowed.

\section{Eugenic Actions}

In response to the financially and socially driven need for population control, legislative action made reproductive control more accessible, which led to mass amounts of voluntary and involuntary sterilizations alike. The legislative actions included: Pro-sterilization laws were passed across Southern states in the 1930s and West Coast groups such as the American Institute of Family Relations garnered more membership and activity through the 1940s. While some states increased availability and access to birth control, NC, VA, OR, and GA passed voluntary sterilization laws ("STERILIZED" 1130). From 1940 into the 1960s, medical regulations for female sterilization, such as the need to consult two doctors and a psychiatrist before the procedure, became less restrictive or non-existent. Furthermore, there were no safeguards such as medical community boards or governmental monitoring in the first three years of publicly funded sterilization procedures (Gutiérrez 60). Also, the American College of Obstetricians and Surgeons canceled the age-parity stipulation, which prevented a woman from having a voluntary sterilization unless her age multiplied by number of children exceeded 120 (Eugenic Nation Faults 223).

Government grants increased for the poor, mainly through Family Planning Services and the Population Research Act in $1970 .{ }^{1}$ A previously private matter became a state and federal-level decision in the name of solidifying social security and creating healthy future citizens (Kline 98).

Between 1965 and 1975, the number of women who had access to family planning resources increased eightfold. ${ }^{2}$ Pro-eugenicists argued that with more education and accessibility to fertility control methods, the greater the freedom people have to make the decision of having a child. However, Malthus argued that "free will" can be obtained only if people are truly making independent decisions for themselves without dependency on welfare or other social services. ${ }^{3}$

Pro-sterilization groups charged themselves with the responsibility to "unburden" "sick" citizens by taking away their ability to reproduce more sick citizens. Sometimes the mentally handicapped would agree to sterilization in exchange for freedom from institutions. From a pro-eugenics standpoint, they were providing these sick people with freedom while taking away the possibility of "burdensome" procreation (McWhorter 256).

For instance, California justified their high sterilization numbers as defending the public health, preserving precious fiscal resources, and mitigating the menace of the "unfit" and "feeble minded," illegitimate, or unmarried ("STERILIZED" 1130). While this methodology speaks to Malthus's point about "all societies being constrained by resources" and even utilitarianism, this approach is does not liberate all people to make independent decisions.

Various pro-population control organizations formed, including the American Eugenics Society, Population Council, Human Betterment Foundation, The Commission of the American Genetic Association, Population Reference Bureau, and Planned Parenthood.

\section{Consequences of Eugenics}

This section serves to provide more insight into how the target populations of the American Eugenics movement were affected. As the numbers of those involuntarily sterilized continued to rise, suspicion rose within the affected groups. Not only women, but populations including the sick and handicapped, felt pressure to conform to sterilization. They most likely felt this pressure because they were socially targeted as "unfit" to reproduce, with hereditary conditions likely to be passed on to future generations. According to Ladelle McWhorter, "The most concentrated of these sterilizations were in mental institutions, but were common practice for all institutions including prisons, reformatories, hospitals, and out-patient clinics across the country" (214). Involuntary sterilization targeted "morons" and the "feeble minded" in the 1910's while efforts were focused on welfare-dependent females later in the century (Eugenic Nation Faults 7). Counter to the "unburdening" of a class, anti-eugenicists saw this as a 
wrongful attack on minority races and ethnicities, low socio-economic status, and poor health.

Notably, many needy women did not make use of new public birth centers in the 1940s and 1950s as proeugenicists and the general public expected. Many poor women saw children as potential assets, as they would eventually bring in additional income later to form multi-income families, yielding more money (Farmer 21). While immigrants were finding their place in society, there was reorganization of current American citizens with poor mental health or "defects." Just as sterilization affected minority immigrants, it also affected 3.5 million "mentally unstable" people, including the "unfit" and handicapped. None of these people requested sterilization, as most could not properly consent due to their disorders.

Of the 65,000 sterilization cases from 1909 and through the 1960s, 20,000 of these procedures occurred in California (Molina 147). Many of these sterilizations targeted Latino and Mexican women. For instance, 180 cases of primarily Spanish-surname women were sterilized while giving childbirth, without written consent. Hospital staff verbally recommended the procedure during late stages of labor while the women were under Demerol and Valium, and performed the tubal ligation after the birth without written record of agreement. Even if there was a signed record, the woman was likely unable to comprehend what she was signing due to the pharmaceutical drugs and language barrier. Some women knew they had had their "tubes tied," but did not understand the permanence for lack of education (Gutierrez 58). One patient was unaware of her sterilization and used an IUD as birth control for a year before realizing she was sterilized (Gutiérrez 58).

Elena Gutiérrez's research on California indicates that between 1968 and 1970, elective hysterectomy increased by $742 \%$, elective tubal ligation by $470 \%$, and tubal ligation after delivery by $151 \%$. Although reports say "elective tubal ligation," "elective" often meant a female patient's verbal consent under heavy drugs. There was no consent, let alone informed consent. Furthermore, three-fourths of women in California who received involuntary sterilization were diagnosed as "sex offending" prostitutes in need of control of their reproductive functions, in the interest of them and their fetus.

The court case, Andrade et al. v. Los Angeles County-USC Medical Center accused LACMC nurses and doctors with battery and "pushing" unlawful sterilization operations between 1968 and 1974. Each of Richard Cruz's (founder of Catholic Chicano activist organization) asked for two million dollars in compensation for what they endured as a result of sterilization (Gutiérrez 59). Andrade et al. v. Los Angeles County-USC Medical Center raised "genocide accusations and condemned medical practitioners on moral grounds" (Gutiérrez 59). The judge ruled in favor of the hospital, stating that there was a "communication breakdown" between patients and medical staff and that "it was unreasonable for the physicians to have been expected to understand Mexican culture well enough to have assessed the effects of the sterilizations on the women's physical and emotional well-being" (Molina 187). This case exemplifies how many women endured human rights abuses and "race-based injustice" in medical and legislative settings (Molina 187).

As previously noted, Germany looked to American eugenics policies as models. Specifically, the California Sterilization Law and Model Eugenic Sterilization Law written by Harry Laughlin (Eugenics Record Office Superintendent) in 1922 informed the German Law, Preventing Hereditarily Ill Progeny. The Model Eugenic Sterilization Lawtargeted those who were mentally retarded, insane, criminal, epileptic, inebriate, diseased, blind, deaf, deformed, and economically dependent. Laughlin's Law was in effect from 1907-1922 (Kuhl 39). While California had been responsible for over half of the performed sterilizations, not all states condoned California's actions : "Including New Jersey and Iowa, sterilization laws were declared unconstitutional, judged to be 'cruel and unusual punishment,' or in violation of equal protection and due process" (Solinger 95).

In North Carolina through the 1950s and 1960s, there were excessive cases of African American women being sterilized for being "unfit" or "incapable of good parenting" (Eugenic Nation Faults 8). Activist Fannie Lou Hamer verified, " $60 \%$ of black women who passed through Sunflower City Hospital in Mississippi were sterilized against their will and often, without their knowledge" (McWhorter 215). Specifically, the 1973 Mary and Katie Relf case in Montgomery, Alabama stood as a public example of unwanted sterilization (Nelson 66). The two black teens were sterilized without proper consent, as the illiterate Mrs. Relf signed an " $x$ " before being informed of the nature of the admitted "shots" to her girls. Upon realizing the implications, the 
parents reported the incident to Southern Poverty Law Center. Once it was public, the nationwide objection to the case led to the involvement of the Federal Department of Health, Education, and Welfare. This led to the suspension of federal funds for sterilization of minors and the "mentally incompetent" until further inspection and proposed regulation (Gutiérrez 61.) This wrongdoing enraged the black community, especially the Black Panther group, who had been active for already a decade, inciting protests against excessive birth control and forced sterilization. The Black Panthers poignantly blamed Family Planning Clinic for being genocidal, as this organization had already sterilized a total of 11 black women who had received federal health subsidies for the procedures (Nelson 86).

Other ethnic minorities such as Native Americans also felt directly subjugated for their ethnic background. Native American women reportedly suffered extreme cases of involuntary sterilization abuse at Indian Health Service clinics by coercion, for fear of losing welfare benefits. Between 1973-1976, 3,406 known US sterilizations accounted for one-fourth of all Native Americans being sterilized. Many of these women were under the age of 21, resulting in the Indian Health Services violating the moratorium established by the Department of Health, Education, and Welfare in 1974 (Gutiérrez 61-2).

Japanese immigrants in California were also closely monitored by eugenics efforts; their birth rates were published comparatively with those of white birth rates in The Los Angeles Tribune and public health department reports, speaking to larger fears of "yellow peril" or the xenophobic belief that East Asian people were a danger to the Western world (Molina 110). The comparison to white births supports the "race suicide" fear of a shrinking white middle class common in eugenics ideology.

The sterilized patient and those who identified with the individual based on class, gender, or race often felt their existences threatened by white supremacist efforts to "purify" and "improve" the nation. "Law enforcers pushed the sexualized bodies of this group into the public sphere, reinforcing the ways that danger and privilege played out across gender and race and class" (Solinger 84-85). Women who could not afford privacy or protection were the ideal targets for society to blame for economic atrophy and general dependence on the government, as well as moral decay.
While many cases went undocumented or unknown, it is important to note that there was a collective solidarity and call for public resources within oppressed communities. According to Molina, "The very forms of racialization that have harmed and excluded communities of color have also, eventually, become focal points for solidarity and collective mobilizations aimed at turning negative ascription and exclusion into positive affirmation and empowerment" (188). One example of such is the gender equality that black women fought for in their homes. Although rarely given credit, matriarchs demanded respect, appreciation, and recognition from their husbands for the physical and emotional stress required for giving birth. Black women were further empowered to take on roles outside motherhood by having access to birth control. Black community leaders urged young women to use contraceptives during the 1920s and 1930s. According to Solinger, "In African American families where women used contraception, the family had a better chance of improving its economic and social status" (95). These leaders were not necessarily pro-sterilization or pro-eugenics, but rather, accepting of the need for fertility control. These women wanted to contribute more than fertility; they wanted to be involved in the political debate and social revolution that was trying to dominate their bodies, and the bodies of women spanning race and class.

\section{Conclusion}

These stigmatized women from various groups share commonalities that allow conclusions to be made about eugenics in 20th century America: Those most affected by involuntary sterilization included the chronically diseased, socially stigmatized, disabled, poor, and women of minority races/ethnicities. However, we must go back to the original reasoning for pro-eugenics actions to truly evaluate the climate in which this controversy lived. Eugenics ideology based off of Malthusianism thrived in the early 1900s because it was an answer to the growing number of people on welfare, and ballooning population numbers due to immigrants and industrialized urbanization. However, eugenics often became a projection of the anxieties regarding racism and classism, most notably in the 1950s and 1960s, not coincidentally at the height of the Civil Rights Movement. Proponents of eugenics were nervous about their own racial and financial identities, 
therefore making it a personal mission to expel, through means of involuntary sterilization, the "less desirable" as in Andrade et al. v. Los Angeles County-USC Medical Center. Few other concrete cases exist because those records were not kept and because the victims of involuntary sterilization lacked the political power and education to take legal action. Eugenics did push the need for reproductive control to the forefront of politics, making free choice a possibility for some women, but mostly only white, middle-class mothers.

From a pro-eugenics standpoint, eugenics pushed public health and resources to public awareness, emphasizing Malthus' point about "societal restrictions" (Farmer). The people responsible for sanctioning voluntary sterilization did so in response to constriction of federal monies and resources. Those responsible for the wrongful involuntary sterilizations were valuing public health or individual rights by restricting who could reproduce. They understood their actions toward sterilizations to be the "unburdening" of racially, socioeconomically, or health disadvantaged people in society. While interpretations of Malthusianism was somewhat morphed to serve racist and elite prejudices, eugenics served a purpose through a reformative period in America when immigration and the societal roles of the "unfit" were reconsidered.

\section{A Retrospective}

The racial elitism surrounding involuntary sterilization allowed for it to swiftly decline by 1975 . However, the 20th century eugenic policies meant to manage America's population have perhaps been more influential in a global sense. Eugenic ideas had spread in the United States by the 1910s-1920s whereas they caught on in Norway, Japan, China, Argentina, and Canada during the 1930s-1950s (Eugenic Nation Faults 6). As noted, American Eugenics were studied and praised by German Nazi efforts. The Commission of the American Genetic Association, headed by Harry H. Laughlin and other pro-eugenics organizations particularly served German eugenics efforts.

Sincerecognizing the wrongful abuse of sterilization, there have been laws since the early 1980s to outlaw involuntary sterilization. Some states such as Oregon, Virginia, and North Carolina affirmed and apologized in the early 2000 s for involuntary sterilizations.
Overall, pro-eugenics beliefs were internalized within our legislative system to protect current and future citizens' quality of life, while serving as a means to control current government spending and public health. Minorities affected by eugenics had reason to feel "attacked": personal attacks were based on race and socio-economic background, as shown by numerical data and court cases, as well as the attitude toward the "unfit" reproducing. There was a fine line with which to treat birth control accessibility and funding from government and social standpoints. Family planning products and resources should inform, empower, and illuminate options for people. However, "it is our moral obligation to minimize the inequalities as much as the laws of nature will allow" (Elwell 26). Careful acknowledgement of freedom and responsibility of all lives is the more balanced path to controlling population. Rather than judging a population in numerical terms, eugenics should acknowledge and avoid exploitation of anyone, whether poor or rich, dark or light-skinned, sick or healthy (The Boston Women's Health Book Collective). These factors were once justification for outright discrimination against people, while simultaneously a set of standards for the American Eugenics Movement from 1910-1975. 


\section{Footnotes}

footnote 1: Historically, $\$ 5$ million in 1965 versus the $\$ 260$ million implemented into the 1979 Medicaid budget (60 Gutiérrez).

footnote 2: In 1965, 450000 women had access to family planning resources compared to the 3.8 million who did in 1975.

footnote 3: I would make a case that Malthus's ideology would align, if not support the dissents of Misters Rehnquist and Stewart Roe v. Wade. They argue that abortion is a "liberty," rather than privacy issue (Shapiro 45).

footnote 4: In the Buck v. Bell decision, the Supreme Court affirmed that the sterilization of the woman in question, Carrie Bell, in fact should have been carried out. "Bell is the probable potential parent of socially inadequate offspring, likewise afflicted, that she may be sexually sterilized without detriment to her general health, and that her welfare and that of society will be promoted by her sterilization," (Buck v. Bell). This simply shows support for sterilization of the "feeble minded" on the federal level.

footnote 5: "Dorothy Roberts argues that cultural constructions of black women as unfit mothers can be grouped into three categories: the careless mother, the matriarchal black unwed mother, and the welfare queen" (Molina 185). The image of the careless black mother emerged during slavery when back women who were assigned as mammies to white children were expected to put their white charges' needs over those of their own children"(Molina 185). Later, when these women joined the workforce after emancipation, they were perceived as having neglected their children. Of course, this construction did not take socioeconomic constraints into consideration, as Molina points out (Molina 185).

"Welfare queens," a term attributed to "lazy," "sexually irresponsible," and "morally questionable," black women has been a long-lasting term that perpetuates the notion that such women bear more children to receive more welfare money (Molina 186). However, more poor white women were living on welfare than black women. However, as Molina points out, these stereotypes continue to exist because of systemic personal scrutiny of these women rather than criticism of the system (Molina 186).

The matriarchal black unwed mother is automatically "unfit" for motherhood as she lacks the "ideal" white femininity and is unmarried, therefore any child she bears is "illegitimate" as the mother.

\section{Works Cited}

Chantrill, Christopher. "Welfare Spending: Charts for US Governments." usgovernmentspending, http:/www. usgovernmentspending.com/social_security_spending_by_ year.html. Accessed 25 Mar. 2015.

Elwell, Frank W. „The Classical Tradition: Malthus, Marx, Weber \& Durkheim. “Claremore, OK: Rogers State University, 2005. Accessed 20 Mar. 2015.

Farmer, Ann. "By their fruits eugenics, population control, and the abortion campaign." Washington, D.C.: Catholic University of America Press, 2008. Accessed 18 Mar. 2015.

Gutiérrez, Elena R. "Fertile Matters: The Politics of MexicanOrigin Women's Reproduction." Austin, TX: University of Texas Press, 2008. Accessed 18 Mar. 2015.

Kline, Wendy. "Building a Better Race: Gender, Sexuality, and Eugenics from the Turn of the Century to the Baby Boom." Berkeley, CA: University of California Press, 2001. Accessed 25 Mar. 2015.

Kuhl, Stefan. "The Nazi Connection: Eugenics, American Racism, and German National Socialism." New York, NY: Oxford University Press, 2002. Accessed 16 Feb. 2017.

Luker, Kristin. "Abortion \& the Politics of Motherhood." Vol. 3. Berkeley, CA: University of California Press, 1985. Print.

Molina, Natalia. "Fit to be Citizens: Public Health and Race in Los Angeles, 1879-1939." Berkeley, CA: Univ. of Cali. Press, 2006. Accessed 16 Feb. 2017.

McWhorter, Ladelle. "Racism and sexual oppression in Anglo-America; a genealogy." Bloomington, IN: Indiana University Press, 2009. Accessed 18 Mar. 2015.

Nelson, Jennifer. "Women of color and the reproductive rights movement." New York, NY: New York University Press, 2003. Accessed 18 Mar. 2015.

Reilly, Philip R. "Involuntary Sterilization in the United States: A Surgical Solution." The Quarterly Review of Biology, vol. 62, no. 2, 1987, pp. 153-170. Accessed 20 Mar. 2015.

Shapiro, Ian., editor. "The Supreme Court Decisions, 19652007." Indianapolis, IN: Hackett Publishing Company, Incorporated, 2008. Print.

Spann, Girardeau A. "Race against the court: Supreme Court and Minorities in Contemporary America." New York, NY: New York University Press, 1993. Print. 
Solinger, Rickie. "Pregnancy and Power." New York, NY: New York University Press, 2005. Print.

Stern, Alexandra. "Eugenic Nation Faults; and frontiers of better breeding in modern America." Berkeley, CA: University of California Press, 2005. Accessed 18 Mar. 2015.

Stern, Alexandra. "STERILIZED in the Name of Public Health: Race, Immigration, and Reproductive Control in Modern California." American Journal of Public Health, vol. 95, no. 7, 2005, pp. 1128-1138. Accessed 25 Mar. 2015.

The Boston Women's Health Book Collective. "Our Bodies, Ourselves.” 35th Ed. New York, NY: Simon \& Schuster, 2005. Print.

"Buck v. Bell." Legal Information Institute, Cornell University Law School. https://www.law.cornell.edu/supremecourt/ text/274/200.html. Accessed 21 April 2015.

"A Science Odyssey, People and Discoveries, Eugenics movement reaches its height 1923." PBS Online, PBS. http://www.pbs.org/wgbh/aso/databank/entries/dh23eu.html. Accessed 24 Mar. 2015.

"Social Darwinism." Encyclopedia Britannica Online. Encyclopedia Britannica Inc., 2014. https://www.britannica. com/topic/social-Darwinism.html. Accessed 24 Mar. 2015. 